\title{
Primary hyperoxaluria diagnosed after kidney transplantation failure: lesson from 3 case reports and literature review
}

\author{
Ruiming $\mathrm{Cai}^{1 \dagger}$, Minzhuang Lin ${ }^{1 \dagger}$, Zhiyong Chen ${ }^{1 \dagger}$, Yongtong Lai ${ }^{1}$, Xianen Huang ${ }^{1}$, Guozhi Zhao ${ }^{1}, X^{\prime}$ uekun Guo ${ }^{1}$, \\ Zhongtang Xiong ${ }^{2}$, Juan Chen ${ }^{2}$, Hui Chen², Qingping Jiang ${ }^{2}$, Shaoyan Liu², Yuexin Yang ${ }^{2}$, Weixiang Liang ${ }^{3}$, \\ Minhui Zou ${ }^{3}$, Tao Liu ${ }^{3}$, Wenfang Chen ${ }^{4}$, Hongzhou Liu ${ }^{5}$ and Juan Peng ${ }^{2^{*}}$ (D)
}

\begin{abstract}
Background: Primary hyperoxaluria $(\mathrm{PH})$ is a rare inborn disorder of the metabolism of glyoxylate, which causes the hallmark production oxalate and forms insoluble calcium oxalate crystals that accumulate in the kidney and other organs. Since the manifestation of PH varies from recurrent nephrolithiasis, nephrocalcinosis, and end-stage renal disease with age at onset of symptoms ranging from infancy to the sixth decade, the disease remains undiagnosed until after kidney transplantation in some cases.

Case presentation: Herein, we report 3 cases of PH diagnosed after kidney transplantation failure, providing the comprehensive clinical course, the ultrasonic image of renal graft and pathologic image of the biopsy, highlighting the relevance of biopsy findings and the results of molecular genetic testing. We also focus on the treatment and the unfavorable outcome of the patients. Meanwhile, we review the literature and show the additional 10 reported cases of PH diagnosed after kidney transplantation. Additionally, we discuss the progressive molecular understanding of the mechanisms involved in PH and molecular therapy.

Conclusions: Overall, the necessity of preoperative screening of PH in all patients even with a minor history of nephrolithiasis and the importance of proper treatment are the lessons we learn from the 3 cases, which prompt us to avoid tragedies.
\end{abstract}

Keywords: Primary hyperoxaluria, Kidney transplantation failure, Calcium oxalate crystals, Case report

\section{Background}

Primary hyperoxalurias $(\mathrm{PH})$ are a group of rare autosomal recessive diseases characterized by the overproduction of oxalate resulting from hereditary enzymatic defects in glyoxylate metabolism, which currently include 3 known types [1-3]. Of the primary hyperoxalurias, approximately $70 \%$ are $\mathrm{PH}$ type 1 (PH1), $10 \%$ are $\mathrm{PH}$ type 2 (PH2), $10 \% \mathrm{PH}$ type 3 (PH3), and $10 \%$ do not have an identified genetic cause [4]. PH1, which is the most frequent and serious disorder due to enzyme

\footnotetext{
* Correspondence: pengjuan1979@yahoo.com; pengjuan1979@gzhmu.edu.cn ${ }^{\dagger}$ Ruiming Cai, Minzhuang Lin and Zhiyong Chen contributed equally to this work.

${ }^{2}$ Department of Pathology, The Third Affiliated Hospital of Guangzhou Medical University, 63 Duobao Road, Guangzhou 510150, People's Republic of China

Full list of author information is available at the end of the article
}

deficit of alanine-glyoxylate aminotransferase (AGT) specific to hepatic peroxisome, is determined by mutations in the AGXT gene. $\mathrm{PH} 2$ and $\mathrm{PH} 3$ are respectively caused by a deficiency of glyoxylate reductase/hydroxypyruvate reductase (GR/HPR) encoded by GRHPR gene and 4-hydroxy-2-oxoglutarate aldolase (HOGA) encoded by HOGA1 gene. Oxalate is excreted through the kidneys, where excessive oxalate precipitates in the form of calcium oxalate $(\mathrm{CaOx})$ crystals, leading to recurrent nephrolithiasis, nephrocalcinosis, chronic kidney disease (CKD) and eventually end-stage renal disease (ESRD) [5]. However, in some cases, high diagnostic suspicion of $\mathrm{PH}$ is proposed after renal graft loss. Here, we present the main steps of 3 cases in the treating experiences of the disease and the management strategies that have been used to control the recurrence of $\mathrm{PH}$ at this time.

(C) The Author(s). 2019 Open Access This article is distributed under the terms of the Creative Commons Attribution 4.0 International License (http://creativecommons.org/licenses/by/4.0/), which permits unrestricted use, distribution, and 
We expect the report might bring more attention to other patients with the same situation.

\section{Case presentation}

\section{Case 1}

A 27-year-old male hypertensive patient was referred to our department on Nov 15, 2017, after right nephrectomy as well as left minimally invasive percutaneous nephrolithotomy (mini-PCNL). With a history of symptomatic kidney stones for more than 10 years and elevated $\mathrm{SCr}$ level for more than 3 years, accompanied with hypertension (peak 170/98 $\mathrm{mmHg}$ ), the patient was scheduled to receive the renal transplantation.

The patient was rehospitalized on Apr 28, 2018, with $\mathrm{SCr} 1487 \mathrm{umol} / \mathrm{L}$ and BUN $33.47 \mathrm{mmol} / \mathrm{L}$ (shown in Additional file 1: Figure S1). He underwent renal transplantation that night, with a deceased donor, which was performed with Zero-Hour Implantation biopsy (ZHIB, as part of the routine renal transplant procedure, shown in Fig. 1a, 200X HE). The patient received standard immunosuppression with mycophenolate mofetil (MMF), tacrolimus (Tac) and methylprednisolone (Methylpred) besides hemodialysis (HD), as well as hypertension treatment. Additionally, he received the follow-up assessments including routine blood tests, blood biochemical analysis and therapeutic drug monitoring regularly
(Additional file 1: Figure S1). However, it was less likely to have improvements in the renal graft function.

Due to the delayed graft function (DGF, SCr 585 umol/L and BUN $30.07 \mathrm{mmol} / \mathrm{L}$ ), the patient received percutaneous needle core biopsy of renal graft on postoperative (post-op) day 46, guided by ultrasonography (USG) (Fig. 1b). Renal graft biopsy revealed acute T cellmediated rejection (TCMR, 2015 Banff 1A) and extensive tubular damage, with the presence of the emerging deposition of $\mathrm{CaOx}$ crystals in the allograft (Fig. 1c, 200X HE and polarized light). Compared with ZHIB, recurrence of $\mathrm{CaOx}$ nephropathy was confirmed in the allograft kidney. Molecular genetic testing of the patient was carried out to identify the pathogenic variants (PV) in $A G X T$ and GRHPR, in whom a homozygous genotype for three missense mutations in the GRHPR gene was found: first, a $\mathrm{C}$ to $\mathrm{T}$ transversion (c.295C > T) in exon 4 resulting in p.(Arg99*), nonsense PV; second, a G to A transversion (c.512G $>\mathrm{A})$ in exon 6 resulting in p.(Arg171His), missense variant of uncertain significance (VUS); third, a G to A transversion (c.211G > A) in exon 2 resulting in p.(Ala71Thr), missense VUS (shown in Table 1 and Fig. 1d). Based on the previous findings a diagnosis of $\mathrm{PH} 2$ was made.

We further analyzed the DNA of the patient's family. Sequencing analysis of the GRHPR gene showed that the

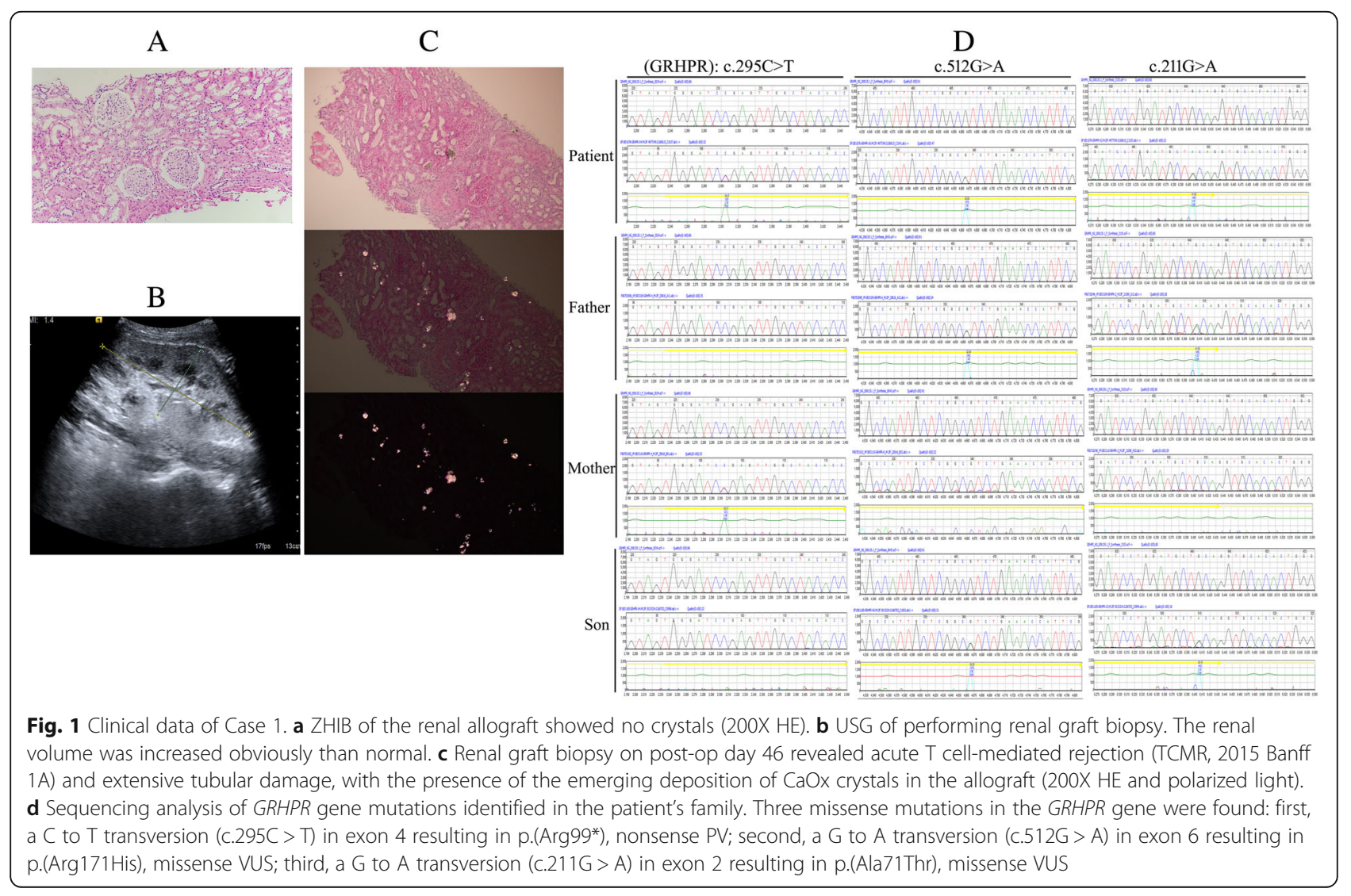


Table 1 GRHPR gene Mutations identified in the patient's family

\begin{tabular}{|c|c|c|c|c|c|}
\hline & Age & GRHPR gene & & & kidney stones \\
\hline & & $\begin{array}{l}\text { c.295C > T ( } p . \text { Arg99Ter), } \\
\text { nonsense PV }\end{array}$ & $\begin{array}{l}\text { c.512G > A (p. Arg171His), } \\
\text { missense VUS }\end{array}$ & $\begin{array}{l}\text { c.211G > A (p. Ala71Thr), } \\
\text { missense VUS }\end{array}$ & \\
\hline the patient & $27 Y$ & + & + & + & +(symptomatic) \\
\hline $\begin{array}{l}\text { the patient's } \\
\text { father }\end{array}$ & $52 Y$ & - & + & + & - \\
\hline $\begin{array}{l}\text { the patient's } \\
\text { mother }\end{array}$ & $50 Y$ & + & - & - & +(asymptomatic) \\
\hline the patient's son & $2 Y 6 \mathrm{M}$ & - & + & + & - \\
\hline the patient's wife & $25 Y$ & - & - & - & - \\
\hline
\end{tabular}

PV (c.295C > T) was also found in the patient's mother, who presented asymptomatic kidney stones. Unfortunately, the other two VUS were detected both in the patient's father and son (shown in Table 1 and Fig. 1d).

The patient was treated with Pyridoxine (PN, Vitamin B6) and temporarily intensive HD besides the basic immunosuppression to suppress oxalate overproduction. Furthermore, for the failure of kidney-alone transplantation (KAT), we recommended the treatment scheme with the combined Liver-Kidney Transplantation (LKT) before the development of systemic oxalosis but was refused by the patient. The patient currently reentered to the maintenance HD in the clinic and looked forward to a chance of LKT in the future.

\section{Case 2}

A 26-year-old male non-hypertensive patient was hospitalized on Aug 11, 2016, with an 8-year history of the elevated SCr, which included a 7-year history of maintenance $\mathrm{HD}$. The next day, attributed to the preoperative SCr $893 \mathrm{umol} / \mathrm{L}$ and BUN $27.32 \mathrm{mmol} / \mathrm{L}$, shown in Additional file 2: Figure S2), he was transplanted with a deceased kidney donor performed with routine ZHIB (Fig. 2a, 200X HE). The patient received standard triple immunosuppression following transplantation as well as the follow-up assessments regularly. Similarly, even though we substituted Cyclosporine A (CsA) for Tac, renal graft gradually developed DGF (SCr $534 \mathrm{umol} / \mathrm{L}$ and BUN $30.06 \mathrm{mmol} / \mathrm{L}$, Additional file 2: Figure S2), and USG-guided renal biopsy was employed on post-op day 38 (Fig. 2b). Deposition of diffuse $\mathrm{CaOx}$ crystals as well as acute TCMR (2015 Banff 2A) was detected in renal graft biopsy (Fig. 2c, 200X HE and polarized light), whereas there were no oxalate crystals in the ZHIB. Molecular genetic testing identified two mutations in the $A G X T$ gene: first, exon 1: c.33dupC (p. Lys12fs), frameshift PV; second, an A to $\mathrm{T}$ transversion (c.215A > T) in exon 2 resulting in p. Asn72Ile, missense VUS. Meanwhile, it was noteworthy that one mutation in the MUT gene (Exon11: c.1897G > C (p. Val633Leu), missense VUS) was detected in the patient. Thus, the patient was diagnosed with $\mathrm{PH} 1$ and treated with $\mathrm{PN}$ (400 mg, iv, QD) and temporary intensive HD.

Owing to the anemia (hemoglobin level, HGB, 57-74 g/L; shown in Additional file 2: Figure S2), bone marrow biopsy was conducted on post-op day 70, which showed intertrabecular spaces occupied by abundant $\mathrm{CaOx}$ crystals (Fig. 2d, 200X HE, 400X HE and polarized light). Apparently, the patient was diagnosed as systemic oxalosis of $\mathrm{PH} 1$ with $\mathrm{CaOx}$ crystals involving both the allograft kidney and bone marrow, the latter is the most crippling site of $\mathrm{CaOx}$ deposition. He was treated with concentrated red blood cells (CRBC) transfusion and recombinant human erythropoietin (rhEPO) to correct the anemia. Moreover, as renal graft loss, he returned to the maintenance HD and received the optimal immunosuppression. Up till now, the patient was investigated for the overall decline in health following allograft failure.

\section{Case 3}

A 34-year-old male hypertensive patient was admitted to hospital on Oct 16, 2015, for the first time because of the elevated SCr level for more than 12 months. Presented with SCr $1222 \mathrm{umol} / \mathrm{L}$ and BUN $24.33 \mathrm{mmol} / \mathrm{L}$ (Additional file 3: Figure S3) as well as hypertension peaked at $180 / 100 \mathrm{mmHg}$, the patient waited for the renal transplantation.

The patient was readmitted to hospital on Jan 5, 2016. He received a kidney allograft on the next day with a deceased donor performed with routine ZHIB (Fig. 3a), followed by post-op standard triple immunosuppression besides HD. Furthermore, the follow-up assessments were executed nearly once a day (Additional file 3: Figure S3). However, the course was unfavorable with DGF emerging. USG-guided renal graft biopsy (Fig. 3b) was performed on post-op day 75, which documented acute TCMR (2015 Banff 2A) and extensive deposits of $\mathrm{CaOx}$ crystals in the interstitial tubule (Fig. 3c, 200X HE and polarized light). In view of the fact that no oxalate crystals deposited in the $\mathrm{ZHIB}$, as well as the history of kidney stones in the recipient, recurrence of $\mathrm{CaOx}$ nephropathy following kidney transplantation was confirmed, which led to the diagnosis 


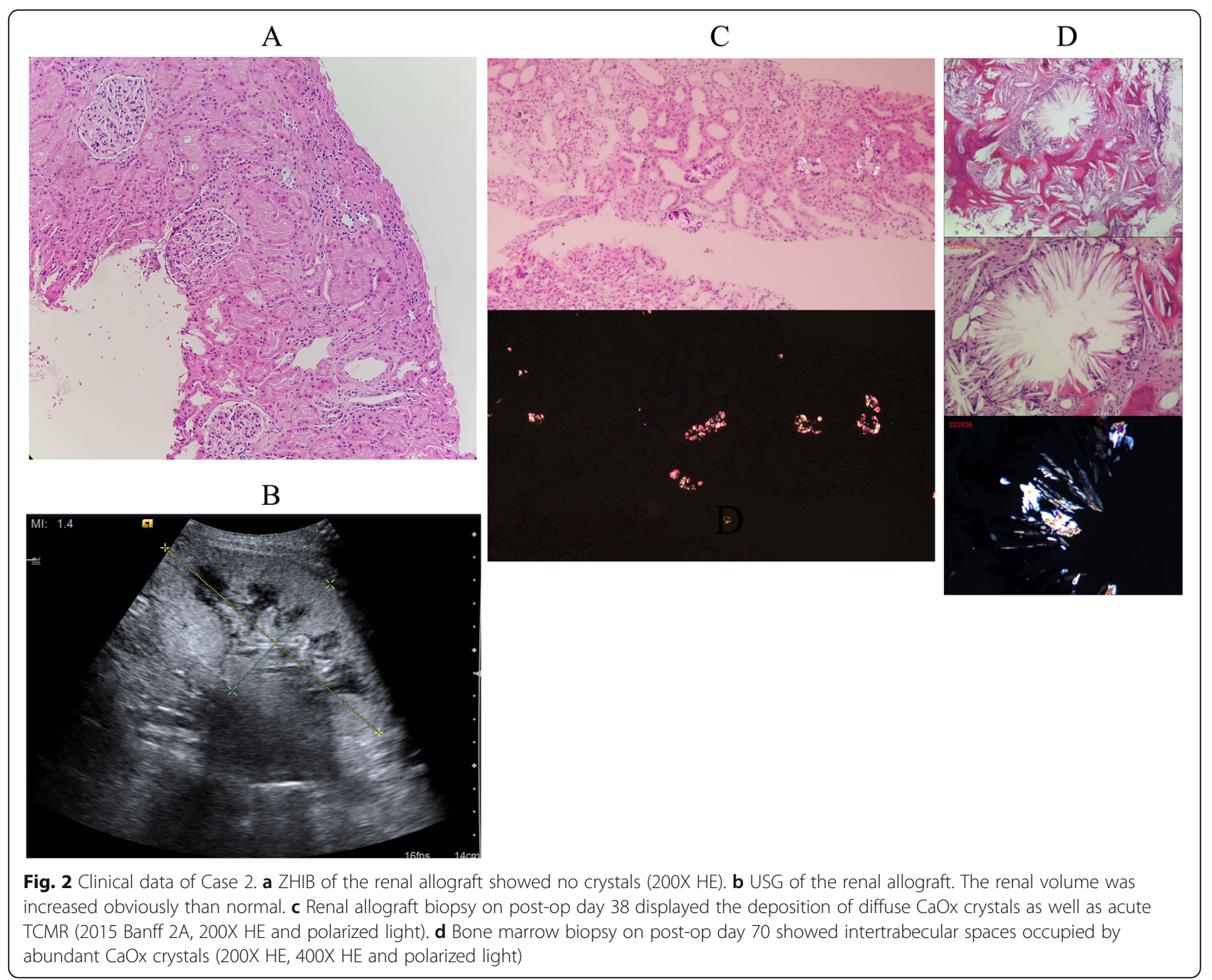

of $\mathrm{PH}$. However, the diagnosis of $\mathrm{PH}$ must depend on the genetic testing. Unfortunately, molecular genetic testing of the patient was not carried out to identify the PV in AGXT, GRHPR or HOGA1 for some reasons.

Although the renal function of the patient was slowly repaired (SCr $260 \mathrm{umol} / \mathrm{L} ; \mathrm{BUN} 14 \mathrm{mmol} / \mathrm{L}$ ), the treatment by HD was ineffective in treating excess oxalate besides the drug immunosuppression. Accompanied by the fever of $39.8^{\circ} \mathrm{C}$ (Body temperature shown in Additional file 3: Figure S3) and intermittent cough, Pneumocystis jirovecii pneumonia (PJP) was confirmed in the patient on May 25 by fiberoptic bronchoscopic (FOB) biopsy (Fig. 3d, 600X HE and Methylamine silver) as well as subsequent Chest $\mathrm{CT}$ examination (Fig. 3e). The patient was initially treated with empirical antiinfection therapy (Micafungin) as well as $\gamma$-globulin. Meanwhile, standard triple immunosuppression was replaced with the pulse intravenous Methylpred. Even though the clinicians enhanced the anti-infection therapy with administration of trimethoprim-sulfamethoxazole
(TMP/SMX) and voriconazole (VOR) orally, as well as meropenem (MEM) was used in the final stage, the patient died of severe pneumonia caused by $P$. jirovecii on Jun 28, 2016.

\section{Discussion and conclusions}

Although the factors of DGF was various, it's necessary to differentiate between DGF secondary to recurrence of PH or other reasons as soon as possible [6]. Given the manifestation of $\mathrm{PH}$ varies from recurrent nephrolithiasis and ESRD during childhood to occasional kidney stones in adulthood, especially to date systemic oxalosis has not been reported in PH3 [1-3], as well as the limitations of the routinely applied methods affect the diagnosis of $\mathrm{PH}$, it still confused us to preoperative diagnosis of PH. Furthermore, the bleeding risk of percutaneous renal biopsy in the patient of ESRD also reduced the possibility to conclude the cause of disease. However, the diagnosis of $\mathrm{PH}$ in case 3 was not recognized until after renal transplant failure with fatal consequences, which led us to confirm 
A

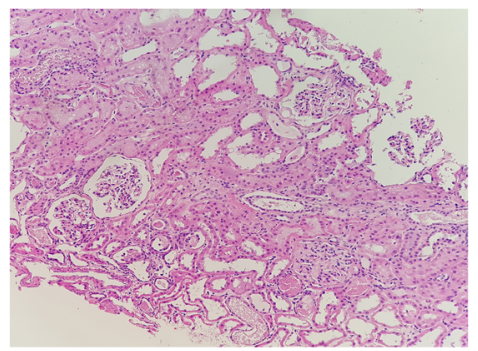

B

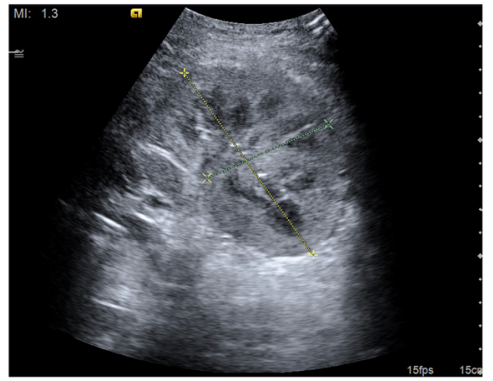

C

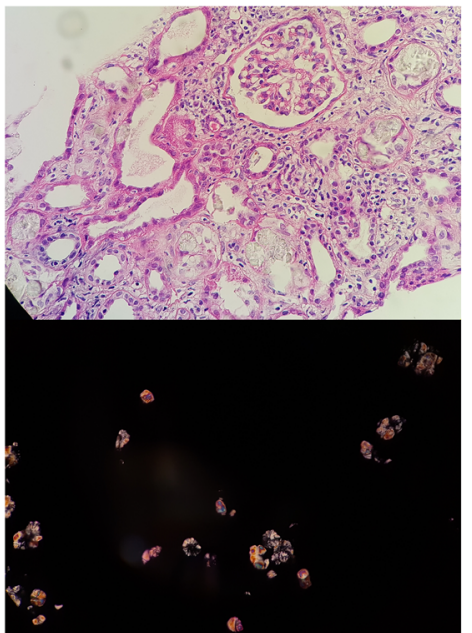

D

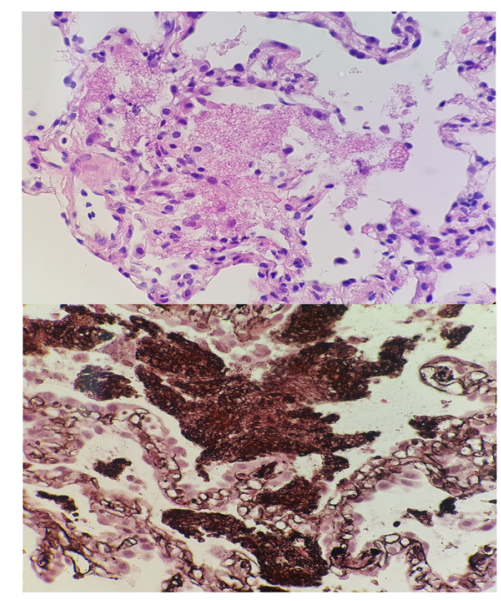

E

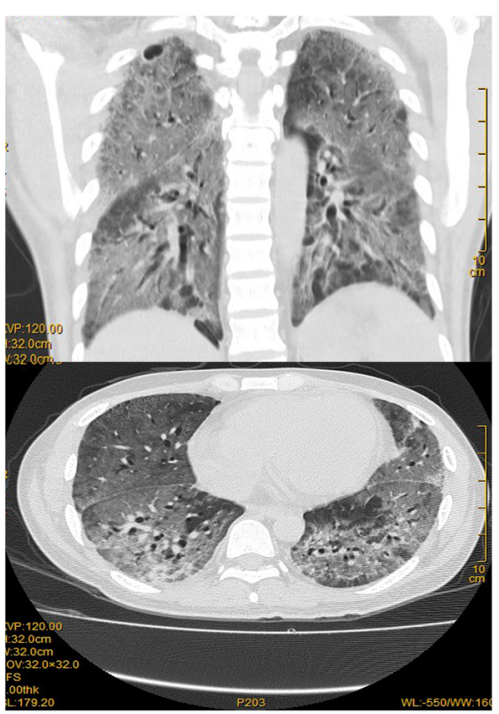

Fig. 3 Clinical data of Case 3. a ZHIB of the renal allograft showed no crystals (200X HE). b USG of the renal allograft. The renal volume was increased obviously than normal. c Renal transplant biopsy on post-op day 75 documented acute TCMR (2015 Banff 2A) and extensive deposits of CaOx crystals in the interstitial tubule (200X HE and polarized light). d Pneumocystis jirovecii pneumonia (PJP) was confirmed in the patient on May 25, 2016 by fiberoptic bronchoscopic (FOB) biopsy, which showed Pneumocystis organisms (600X HE and Methylamine silver). e Chest CT examination demonstrated diffuse ground-glass opacities (GGO)

the importance of selective screening before planning for kidney transplantation in the population with clinical and biochemical suspicion of $\mathrm{PH}$. Molecular genetic testing was adopted for these people to identify the PV in $A G X T$, GRHPR and HOGA1 gene, which were respectively the genetic determinants of PH1, 2 and 3. Despite we paid more attention to the similar situation, there were still overlooked or delayed affairs happened in our hospital such as case 1 and 2. Both patients had developed into the early post-transplant renal graft loss by DGF secondary to recurrence of $\mathrm{PH}$.
Since Riksen et al. first reported the case of a Yugoslav renal transplant patient, who was confirmed the diagnosis of PH1 after a second renal transplant [7], we revealed an additional 12 reported cases of $\mathrm{PH}$ diagnosed after kidney transplantation by a comprehensive search of published English-language literature (Table 2) [8-15]. The early post-transplant renal graft loss, including a return to maintenance HD, re-transplantation, or patient death, had occurred in most cases. Considering the poor outcomes when crystalline nephropathy recurrence after transplantation [16], it is obviously optimal to recognize $\mathrm{PH}$ by 


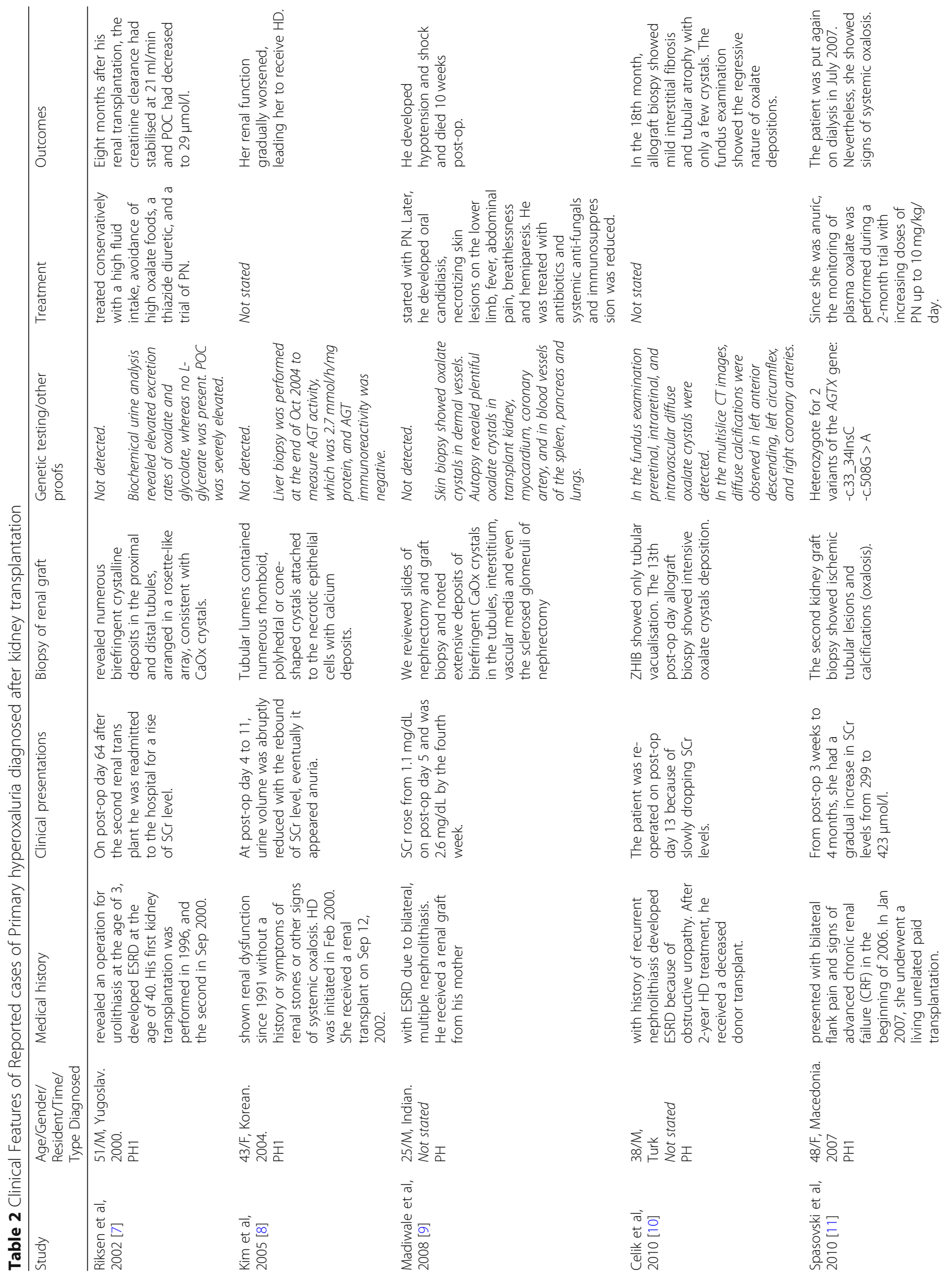




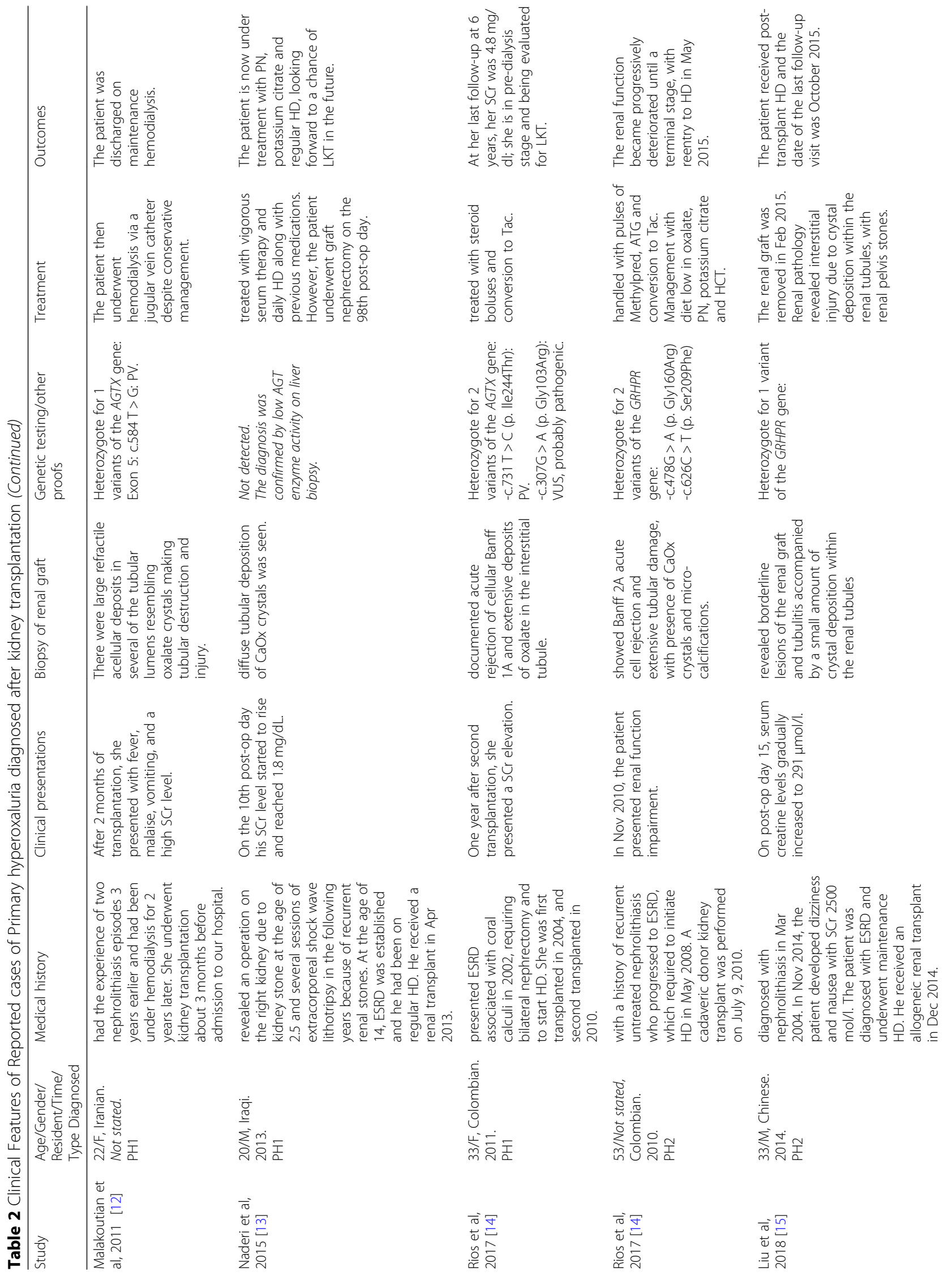




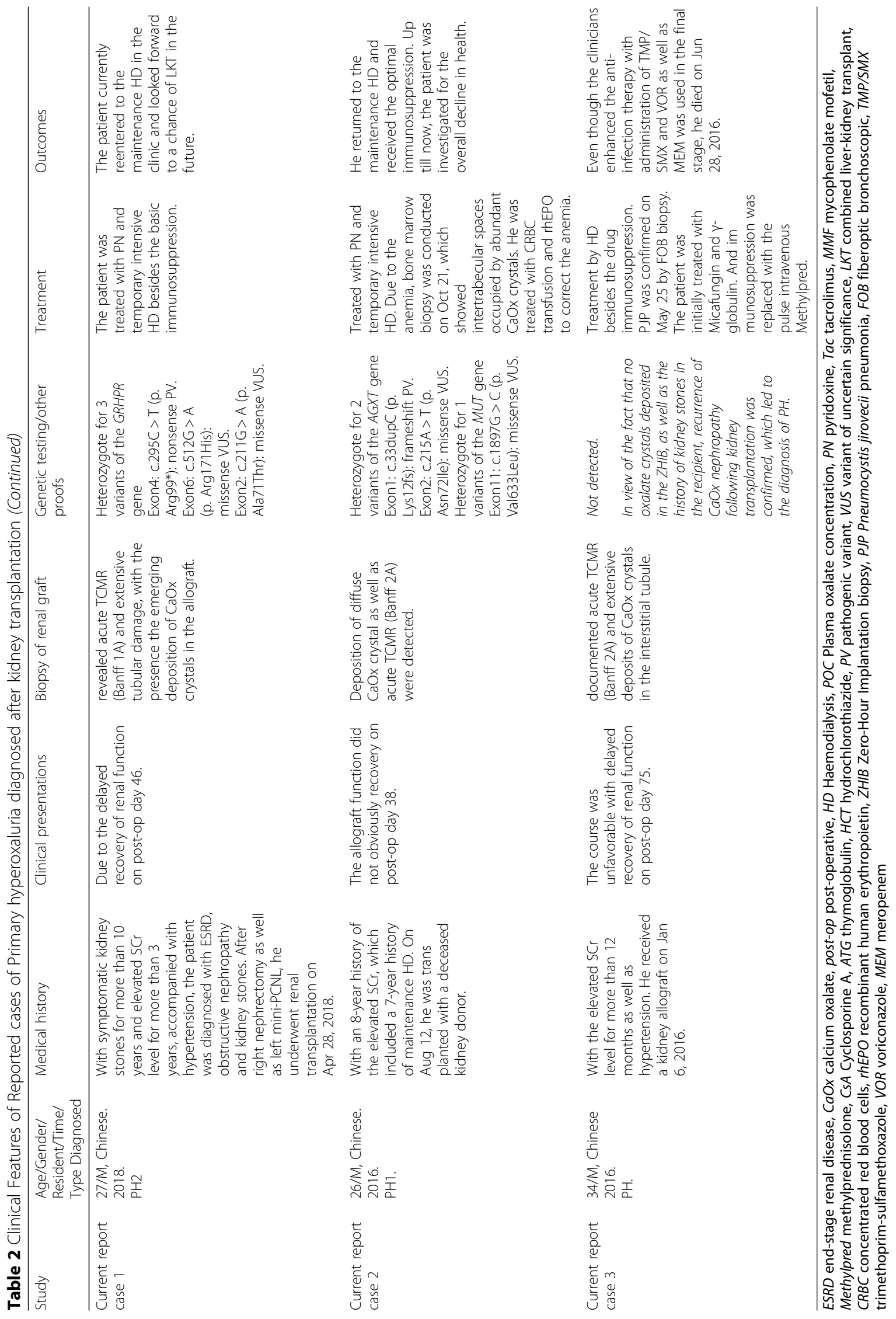


molecular genetic testing as early as possible, in order to implement specific therapies and strategies aimed at lowering oxalate levels.

Recent decades have witnessed the molecular understanding of the mechanisms involved in $\mathrm{PH} . \mathrm{PH} 1$ is determined by mutations of AGXT gene (Located: 2q 37.3, contains 11 exons), which is wide phenotypic variability. Out of 253 known PVs in 358 variants of $A G X T$ gene, 4 PVs of $A G X T$ in PH1 patients (c.33dupC, c.454T $>\mathrm{A}$, c.508G $>A$, and c.731T>C) were the most common in the reported PH1 mutations in the literature (http:// www.ncbi.nlm.nih.gov/clinvar/). In the case 2, we detected the PV of $A G X T$ gene (c.33dupC), which was last reviewed on Oct 9, 2015, and on top of that we first reported the novel mutation of $A G X T$ gene (c.215A $>$ T). Apart from this, the potential role of the missense mutation in MUT gene (c.1897G > C) in the development of the patient's disease needed further confirmation.

The diagnosis of $\mathrm{PH} 2$ is established by the identification of PV in GRHPR (Located: 9p13.2, contains 11 exons). Out of 81 known PVs in 159 variants of GRHPR gene, 3 PVs in PH2 patients (c.103delG, c.295C > T, and c.864_865delTG) were the most common in the reported PH2 mutations in the literature (http://www.ncbi. nlm.nih.gov/clinvar/). In our case 1, we not only confirmed the PV (c.295C>T, which was last reviewed on Nov 2, 2017) inherited from his mother, but also detected the novel mutations (c.512G > A, c. $211 \mathrm{G}>\mathrm{A}$ ) inherited from his father and passed them to his son. Although both the patient's father and his son were the asymptomatic carrier without renal stones, they still needed closely follow-up observation.

The diagnostic findings of PH3 are PV in HOGA1 (Located: 10q24.2, contains 7 exons). Out of 42 known PVs in 118 variants of HOGA1 gene, 2 PVs in PH3 patients (c.700+5G $>$ T and c.944_946delAGG) were the most common in the reported PH3 mutations in the literature (http://www.ncbi.nlm.nih.gov/clinvar/). PH3 has not been reported yet in our hospital till now.

In the light of the poor prognosis of the recurrent $\mathrm{PH}$ and the limitations of conservative measures (including overhydration, crystallization inhibitors and PN) as well as the risk of renal replacement therapy (despite an inevitable fact that shows the superiority of LKT over KAT) $[17,18]$, the confirmation of the genetic defect in $\mathrm{PH}$ patients had urged us to seek novel therapeutic approaches to control the disease without the need for LKT or KAT, and the emerging molecular therapy for $\mathrm{PH}$ may be feasible. The molecular therapy, such as enzyme replacement, substrate reduction, proteostasis regulation, as well as gene and cell therapy, may fix the mess that the overplus of oxalate is produced by mutant hepatocytes owing to the abnormal metabolism of glyoxylate in $\mathrm{PH}$ patients [19].
Despite the replacement enzyme need to be targeted to a specific subcellular organelle, the peroxisome, and the excessive oxalate would proceed to be formed in those untargeted hepatocytes, Roncador et al. [20] described the delivering AGT via the conjugation with PEG-PGA to the peroxisomes, as well as Mesa-Torres et al. [21] reported the use of pharmacological ligands aimed to increase AGT stability as therapies for PH1, which suggested enzyme replacement therapy (ERT) might play a role in $\mathrm{PH}$.

Glycolate oxidase (GO) is the only member of the $\alpha$ hydroxyacid oxidase family that transforms glycolate into glyoxylate [22]. Martin-Higueras et al. presented proof-of-concept evidence for substrate reduction therapy (SRT) in PH1 that GO inhibitors reduced the oxalate production by inhibiting GO activity [23]. Dutta et al. verified that inhibition of GO with Dicer-substrate siRNA had reduced $\mathrm{CaOx}$ deposition in a mouse model of PH1 [24]. Moreover, several ongoing clinical trials are currently exploring the safety and effectiveness of the therapy of the GO silencing in PH patients [19].

It's well known that the administration of pyridoxine hydrochloride (vitamin B6) proposed as chaperone- proteostasis regulator therapy (CPRT) in PH1 several decades ago was ascribed to the fact that pyridoxal $5^{\prime}$ phosphate (PLP, a form of vitamin B6) is a cofactor for AGT. Even more, other B6 vitamers, such as pyridoxamine (PM) and pyridoxal (PL), were reported to be more effective than $\mathrm{PN}$ in rescuing folding-defective variants of human alanine in PH1 $[25,26]$.

Gene therapy in PH has been tested in several preclinical studies [27, 28]. Recently Castello et al. investigated Helper-dependent adenoviral vectors (HDAdV) for liverdirected gene therapy in the mouse PH1 model to achieve long-term liver transgene expression and correction of hyperoxaluria after a single injection [29].

Since KAT does not correct the underlying metabolic defect, just like the 3 cases we reported, transplant recipients have a high risk of recurrence of crystalline nephropathy which can lead to graft loss, as well as LKT is limited by the scarcity of organs and the need for long-term immunosuppression [30], Zapata-Linares et al. attempted the cell therapy by using hepatocytes generated from human induced pluripotent stem cells (hiPSCs) derived from a PH1 patient with p. I244T mutation as vehicles for ex vivo gene therapy using autologous cells to circumvent the immunosuppression [31].

In summary, our above case report indicated that diagnosed $\mathrm{PH}$ after kidney transplantation failure prompts us to execute preoperative screening of $\mathrm{PH}$ in all patients even with a minor history of nephrolithiasis and seek the better methods of treatments to avoid tragedies. 


\section{Additional files}

Additional file 1: Figure S1. The results of laboratory tests of case 1. The SCr and BUN of the patient were charted serially, showing the course of the delayed graft function (DGF), and accompanied by the occasional fever of $37.7^{\circ} \mathrm{C}$. Meanwhile, the levels of WBC count and neutrophils significantly fluctuated, and the Tac blood concentrations ranged from 2.6 to $19.3 \mathrm{ng} / \mathrm{ml}$. (TIF $2161 \mathrm{~kb}$ )

Additional file 2: Figure S2. The results of laboratory tests of case 2. The SCr and BUN of the patient were charted serially, showing the development of DGF, even re-progression to ESRD. In the meantime, the levels of WBC count and neutrophils, as well as HGB fluctuated significantly. The Tac blood concentrations ranged from 5.6 to $9.0 \mathrm{ng} / \mathrm{ml}$ before replaced by Cyclosporine A (CsA), which hereafter ranged from 82.7 to $258.3 \mathrm{ng} / \mathrm{ml}$. (TIF $2269 \mathrm{~kb}$ )

Additional file 3: Figure S3. The results of laboratory tests of case 3. The $\mathrm{SCr}$ and BUN of the patient were charted serially, showing the emergence of DGF and the renal transplant failure with fatal consequences, accompanied by the fever of $39.8^{\circ} \mathrm{C}$. Meanwhile, the levels of WBC count and neutrophils fluctuated significantly. The Tac blood concentrations ranged from 3.3 to $15.9 \mathrm{ng} / \mathrm{ml}$ before it was stopped. (TIF $2530 \mathrm{~kb}$ )

\section{Abbreviations}

ATG: Thymoglobulin; BUN: Blood urea nitrogen; CaOx: Calcium oxalate; CRBC: Concentrated red blood cells; CsA: Cyclosporine A; d: day(s); DGF: Delayed graft function; ESRD: End-stage renal disease; FOB: Fiberoptic bronchoscopic; H\&E: Hematoxylin and eosin; HD: Haemodialysis; HGB: Hemoglobin; IV: Intravenously; KAT: Kidney-alone transplantation; LKT: combined Liver-Kidney Transplantation; MEM: Meropenem; Methylpred: Methylprednisolone; MMF: Mycophenolate mofetil; PH: Primary hyperoxaluria; PJP: Pneumocystis jirovecii pneumonia; post-op: post-operative; PV: Pathogenic variant; QOD: Every other day; rhEPO: recombinant human erythropoietin; SCr: Serum creatinine; Tac: Tacrolimus; TCMR: T cell-mediated rejection; TMP/SMX: Trimethoprim-sulfamethoxazole; USG: Ultrasonography; VOR: Voriconazole; VUS: Variant of uncertain significance; WBC: White blood cell(s); ZHIB: Zero-Hour Implantation biopsy

\section{Acknowledgments}

We thank the Guangzhou Kingmed Center for Clinical Laboratory Co., Ltd. for DNA sequencing analysis. And we thank the Key Laboratory of Reproduction and Genetics of Guangdong Higher Education Institutes for the data analysis.

\section{Authors' contributions}

JP designed the study, wrote and revised the manuscript, with input from $R C, M L, Z C, Y L, X H, G Z, X G, J C, Z X, H C, Q J, S L, Y Y, W L, M Z, T L, W C$ and HL. Clinical data were collected and analyzed by RC, ML, ZC, YL, XH, GZ and XG. $\mathrm{RC}$ participated in revising the report critically for the important intellectual content. ML and ZC participated in designed the study. RC, ML and ZC contributed equally to this work. The renal transplant biopsy was diagnosed by JP, JC and HC. The bone marrow biopsy and the FOB biopsy was respectively diagnosed by ZX and QJ. Hematoxylin and eosin (H\&E) staining, and Methylamine silver staining were fulfilled by $S L$ and $Y Y$. The ultrasonography analysis was carried out by $W L, M Z$ and $T L$. HL performed the analysis of the results of the DNA sequencing. The DNA sequencing analysis of the case 2 was supported by WC. In addition, she participated in revising the grammar of the report. All authors have read and approved the final manuscript.

\section{Funding}

This report was supported by the Guangdong Natural Science Foundation of China, No. 2016A030310280 for the collection and analysis of the part of the clinical data.

\section{Availability of data and materials}

The raw data that support the findings of this report are available from The Third Affiliated Hospital of Guangzhou Medical University and Guangzhou Kingmed Center for Clinical Laboratory Co., Ltd. but restrictions apply to the availability of these data, which were used under license for the current study, and so are not publicly available. Data are however available from the authors upon reasonable request and with permission of The Third Affiliated Hospital of Guangzhou Medical University and Guangzhou Kingmed Center for Clinical Laboratory Co., Ltd.

\section{Ethics approval and consent to participate}

All procedures were performed according to the guidelines of the Chinese transplant ethics. And we provided definitely the confirmation that the donor was not sourced from executed prisoners, but deceased donors.

\section{Consent for publication}

Written informed consent was obtained from the patients for publication of this case report and any accompanying images. A copy of the written consent is available for review by the Editor-in-Chief of this journal.

\section{Competing interests}

The authors declare that they have no competing interests.

\section{Author details}

${ }^{1}$ Department of Organ Transplantation, The Third Affiliated Hospital of Guangzhou Medical University, Guangzhou 510150, China. ²Department of Pathology, The Third Affiliated Hospital of Guangzhou Medical University, 63 Duobao Road, Guangzhou 510150, People's Republic of China. ${ }^{3}$ Department of Ultrasound, The Third Affiliated Hospital of Guangzhou Medical University, Guangzhou 510150, China. ${ }^{4}$ Department of Pathology, The First Affiliated Hospital of Sun Yat-sen University, Guangzhou 510080, China. ${ }^{5}$ Department of Clinical Laboratory, Guangzhou Kingmed Center for Clinical Laboratory Co., Ltd, Guangzhou 510330, China.

Received: 4 November 2018 Accepted: 28 May 2019 Published online: 18 June 2019

\section{References}

1. Milliner DS, Harris PC, Cogal AG, Lieske JC. Primary Hyperoxaluria type 1. In: Adam MP, Ardinger HH, Pagon RA, Wallace SE, Bean LJH, Stephens K, Amemiya A, editors. GeneReviews ${ }^{\oplus}$ [Internet]. Seattle: University of Washington; 1993-2018. Initial Posting: June 19, 2002; Last Update: November 30, 2017.

2. Rumsby G, Hulton SA. Primary Hyperoxaluria type 2. In: Adam MP, Ardinger $\mathrm{HH}$, Pagon RA, Wallace SE, Bean LJH, Stephens K, Amemiya A, editors. GeneReviews ${ }^{\circledR}$ [Internet]. Seattle: University of Washington; 1993-2018. Initial Posting: December 2, 2008; Last Update: December 21, 2017.

3. Milliner DS, Harris PC, Lieske JC. Primary Hyperoxaluria type 3. In: Adam MP, Ardinger HH, Pagon RA, Wallace SE, Bean LJH, Stephens K, Amemiya A, editors. GeneReviews ${ }^{\circledast}$ [Internet]. Seattle: University of Washington; 19932018. Initial Posting: September 24, 2015.

4. Hopp K, Cogal AG, Bergstralh EJ. Et al; on behalf of the rare kidney stone consortium. Phenotype-genotype correlations and estimated carrier frequencies of primary Hyperoxaluria. J Am Soc Nephrol. 2015;26(10):2559-70.

5. Lorenzo V, Torres A, Salido E. Primary hyperoxaluria. Nefrologia. 2014;34(3): 398-412.

6. Bollée G, Cochat P, Daudon M. Recurrence of crystalline nephropathy after kidney transplantation in APRT deficiency and primary hyperoxaluria. Can J Kidney Health Dis. 2015;2:31.

7. Riksen NP, Timmers HJ, Assmann KJ, et al. Renal graft failure due to type 1 primary hyperoxaluria. Neth J Med. 2002;60(10):407-10.

8. $\mathrm{Kim} \mathrm{HH}, \mathrm{Koh} \mathrm{HI}, \mathrm{Ku} \mathrm{Bl}$, et al. Late-onset primary hyperoxaluria diagnosed after renal transplantation presented with early recurrence of disease. Nephrol Dial Transplant. 2005;20(8):1738-40.

9. Madiwale C, Murlidharan P, Hase NK. Recurrence of primary hyperoxaluria: an avoidable catastrophe following kidney transplant. J Postgrad Med. 2008; 54(3):206-8

10. Celik G, Sen S, Sipahi S, et al. Regressive course of oxalate deposition in primary hyperoxaluria after kidney transplantation. Ren Fail. 2010;32(9):1131-6.

11. Spasovski G, Beck BB, Blau N, et al. Late diagnosis of primary hyperoxaluria after failed kidney transplantation. Int Urol Nephrol. 2010;42(3):825-9.

12. Malakoutian T, Asgari M, Houshmand $M$, et al. Recurrence of primary hyperoxaluria after kidney transplantation. Iran J Kidney Dis. 2011;5(6):429-33.

13. Naderi G, Tabassomi F, Latif A, et al. Primary hyperoxaluria type 1 diagnosed after kidney transplantation: the importance of pre-transplantation metabolic screening in recurrent urolithiasis. Saudi J Kidney Dis Transpl. 2015;26(4):783-5. 
14. Rios JFN, Zuluaga M, Higuita LMS, et al. Primary hyperoxaluria diagnosed after kidney transplantation: report of 2 cases and literature review. J Bras Nefrol. 2017;39(4):462-6.

15. Liu S, Gao B, Wang G, et al. Recurrent primary hyperoxaluria type 2 leads to early post-transplant renal function loss: a case report. Exp Ther Med. 2018; 15(4):3169-72

16. Bergstralh EJ, Monico CG, Lieske JC. Et al; IPHR investigators. Transplantation outcomes in primary Hyperoxaluria. Am J Transplant. 2010;10(11):2493-501.

17. Moray G, Tezcaner T, Özçay F, et al. Liver and kidney transplant in primary hyperoxaluria: a single center experience. Exp Clin Transplant. 2015;13(Suppl 1):145-7.

18. Compagnon P, Metzler $P$, Samuel $D$, et al. Long-term results of combined liver-kidney transplantation for primary Hyperoxaluria type 1: the French experience. Liver Transpl. 2014;20(12):1475-85.

19. Martin-Higueras C, Torres A, Salido E. Molecular therapy of primary hyperoxaluria. J Inherit Metab Dis. 2017:40(4):481-9.

20. Roncador A, Oppici E, Talelli M, et al. Use of polymer conjugates for the intraperoxisomal delivery of engineered humanalanine: glyoxylate aminotransferase as a protein therapy for primary hyperoxaluria type I. Nanomedicine. 2017;13(3):897-907.

21. Mesa-Torres N, Salido E, Pey AL. The lower limits for protein stability and foldability in primary hyperoxaluria type I. Biochim Biophys Acta. 2014 1844(12):2355-65.

22. Frishberg $Y$, Zeharia $A$, Lyakhovetsky $R$, et al. Mutations in HAO1 encoding glycolate oxidase cause isolated glycolic aciduria. J Med Genet. 2014;51(8): 526-9.

23. Martin-Higueras C, Luis-Lima S, Salido E. Glycolate oxidase is safe and efficient target for substrate reduction therapy in a mouse model of primary Hyperoxaluria type I. Mol Ther. 2016;24(4):719-25.

24. Dutta C, Avitahl-Curtis N, Pursell N, et al. Inhibition of Glycolate oxidase with dicer-substrate siRNA reduces calcium oxalate deposition in a mouse model of primary Hyperoxaluria type 1. Mol Ther. 2016;24(4):770-8.

25. Pey AL, Albert A, Salido E. Protein homeostasis defects of alanine-glyoxylate aminotransferase: new therapeutic strategies in primary hyperoxaluria type I. Biomed Res Int. 2013;2013:687658

26. Oppici E, Fargue $\mathrm{S}$, Reid ES, et al. Pyridoxamine and pyridoxal are more effective than pyridoxine in rescuing folding-defective variants of human alanine: glyoxylate aminotransferase causing primary hyperoxaluria type I. Hum Mol Genet. 2015:24(19):5500-11.

27. Salido EC, Li XM, Lu Y, et al. Alanine-glyoxylate aminotransferase-deficient mice, a model for primary hyperoxaluria that responds to adenoviral gene transfer. Proc Natl Acad Sci U S A. 2006;103(48):18249-54.

28. Salido E, Rodriguez-Pena M, Santana A, et al. Phenotypic correction of a mouse model for primary hyperoxaluria with adeno-associated virus gene transfer. Mol Ther. 2011;19(5):870-5.

29. Castello R, Borzone R, D'Aria S, et al. Helper-dependent adenoviral vectors for liver-directed gene therapy of primary hyperoxaluria type 1. Gene Ther. 2016:23(2):129-34

30. Kivelä JM, Räisänen-Sokolowski A, Pakarinen MP, et al. Long-term renal function in children after liver transplantation. Transplantation. 2011;91(1): $115-20$

31. Zapata-Linares N, Rodriguez S, Salido E, et al. Generation and characterization of human iPSC lines derived from a primary Hyperoxaluria type I patient with p. I244T mutation. Stem Cell Res. 2016;16(1):116-9.

\section{Publisher's Note}

Springer Nature remains neutral with regard to jurisdictional claims in published maps and institutional affiliations.

Ready to submit your research? Choose BMC and benefit from:

- fast, convenient online submission

- thorough peer review by experienced researchers in your field

- rapid publication on acceptance

- support for research data, including large and complex data types

- gold Open Access which fosters wider collaboration and increased citations

- maximum visibility for your research: over $100 \mathrm{M}$ website views per year

At $\mathrm{BMC}$, research is always in progress.

Learn more biomedcentral.com/submissions 